\title{
Prognostic significance of peritumoral fibrosis after resection of pancreatic head cancer
}

\author{
PENG CHEN $^{1 *}$, YOUMEI WANG $^{2 *}$, XIAOSAN FANG ${ }^{1}$, XIAOMING WANG $^{1}$ and GUANNAN WANG ${ }^{1}$ \\ ${ }^{1}$ Department of Hepatobiliary Surgery, The First Affiliated Hospital of Wannan Medical College, Wuhu, Anhui 241001; \\ ${ }^{2}$ Department of Pharmacy, The Second Affiliated Hospital of Zhejiang University School of Medicine, \\ Changxing Campus, Huzhou, Zhejiang 313100, P.R. China
}

Received September 20, 2019; Accepted November 19, 2019

DOI: $10.3892 / \mathrm{ol} .2019 .11181$

\begin{abstract}
Prognostic value of peritumoral fibrosis (PF) in pancreatic head cancer after resection was evaluated. A total of 143 pancreatic cancer patients who underwent tumor resection were enrolled. All patients underwent routine preoperative examination, including contrast-enhanced computed tomography (CT) or magnetic resonance imaging (MRI). Patients receiving preoperative chemoradiation were excluded because it affects the proportion of fibrosis and cancer cells. Histopathological confirmation and classification of pancreatic head cancer (PHC) was made according to the standards of World Health Organization and the American Joint Committee on Cancer (AJCC). The presence of fibrosis was assessed histologically, and correlated with the clinicopathological characteristics and overall survival using univariate Kaplan-Meier analysis and a stepwise multivariable Cox regression model. Vein resection, resection margin, grading, nodal status, preoperative CA19-9 levels and PF were significantly associated with overall survival. Multivariate analysis showed that all the aforementioned were independent predictive factors of survival. In addition, the survival of patients with PF was significantly worse compared to those without (HR 1.392; $\mathrm{P}=0.027$ ). Tumor necrosis is a valuable prognostic tool that can be included in the routine post-resection histopathological evaluation of pancreatic head cancer patients.
\end{abstract}

Correspondence to: Dr Xiaosan Fang or Dr Xiaoming Wang, Department of Hepatobiliary Surgery, The First Affiliated Hospital of Wannan Medical College, 2 Zheshan West Road, Jinghu, Wuhu, Anhui 241001, P.R. China

E-mail:wyr9hb@163.com

E-mail: xmwang@wnmc.edu.cn

*Contributed equally

Key words: pancreatic head cancer, PF, tumor necrosis, predicted survival

\section{Introduction}

Pancreatic cancer is the fifth most commonly diagnosed cancer and the fourth leading cause of cancer-related mortality worldwide (1). Because of its characterizations of aggressive and early dissemination, the overall 5-year survival rate of pancreatic cancer patients is a dismal 3-5\%, which increases to $15-25 \%$ among those who undergo curative resection $(2,3)$. However, the mortality rate remains high and has not shown any obvious improvement in the past few decades. A better understanding of the underlying molecular mechanisms of this cancer might contribute to demarcate the patients into different prognostic groups, as well as identify novel markers associated with prognosis.

Hypoxia is one of the common features of human cancers, and manifested histologically by necrosis and peritumoral fibrosis (PF) (4-6). Tumor necrosis has been identified as a marker of poor prognosis in renal, breast, lung, pancreatic and colorectal cancers (7-10), whereas PF affects the outcome and prognosis of inflammatory and hematopoietic disorders $(11,12)$. No study so far has analyzed the formation of $\mathrm{PF}$ and its potential relationship to the clinicopathological parameters and prognosis of pancreatic head cancer (PHC). The present study evaluated the clinical significance and prognostic value of $\mathrm{PF}$ in $\mathrm{PHC}$ patients after resection.

\section{Patients and methods}

Patients and tumor samples. Total of 143 samples from patients with PHC resection between January 2007 and December 2011 at the Department of Hepatobiliary Surgery, Yi Ji Shan Hospital of Wannan Medical College were included in the present study. All patients with $\mathrm{PHC}$ received routine preoperative work-up including a contrast-enhanced computed tomography (CT) or magnetic resonance imaging (MRI). The contraindications for curative resection included metastases, complete occlusions of the superior-mesenteric/portal vein or arterial infiltration ( $>180^{\circ}$ circumference), except tumor contact to the portal vein alone. All the patients with PHC underwent the Kausch-Whipple procedure and standard lymphadenectomy along the right side of the superior mesenteric artery, the hepatoduodenal ligament, and the celiac trunk/upper pancreatic margin. PHC was confirmed histopathologically and classified according to the 
Table I. Relationship between clinicopathological characteristics and presence of peritumoral fibrosis.

\begin{tabular}{|c|c|c|c|c|}
\hline \multirow[b]{2}{*}{ Characteristics } & \multirow[b]{2}{*}{ No. of patients } & \multicolumn{2}{|c|}{ Peritumoral fibrosis } & \multirow[b]{2}{*}{ P-value } \\
\hline & & Presence & Absence & \\
\hline Age (years) & & & & 0.404 \\
\hline$<70$ & 104 & 64 & 40 & \\
\hline$\geq 70$ & 39 & 21 & 18 & \\
\hline Sex & & & & 0.663 \\
\hline Female & 61 & 43 & 18 & \\
\hline Male & 82 & 55 & 27 & \\
\hline Intraoperative blood transfusion & & & & 0.918 \\
\hline Yes & 42 & 30 & 12 & \\
\hline No & 101 & 73 & 28 & \\
\hline Vein resection & & & & 0.820 \\
\hline Yes & 25 & 14 & 11 & \\
\hline No & 118 & 69 & 49 & \\
\hline Grading & & & & 0.814 \\
\hline $\mathrm{G} 1 / 2$ & 114 & 72 & 42 & \\
\hline $\mathrm{G} 3 / 4$ & 29 & 19 & 10 & \\
\hline T stage & & & & 0.067 \\
\hline $\mathrm{T} 1 / 2$ & 21 & 14 & 7 & \\
\hline $\mathrm{T} 3 / 4$ & 122 & 102 & 20 & \\
\hline Resection margin & & & & 0.140 \\
\hline Negative & 105 & 72 & 33 & \\
\hline Positive & 38 & 21 & 17 & \\
\hline Nodal status & & & & 0.678 \\
\hline Negative & 82 & 51 & 31 & \\
\hline Positive & 61 & 40 & 21 & \\
\hline Preoperative CA19-9 (U/ml) & & & & 0.842 \\
\hline$<37$ & 21 & 14 & 7 & \\
\hline$\geq 37$ & 122 & 84 & 38 & \\
\hline No. of examined nodes & & & & 0.327 \\
\hline$<12$ & 52 & 23 & 29 & \\
\hline$\geq 12$ & 91 & 48 & 43 & \\
\hline Complications & & & & 0.339 \\
\hline Yes & 70 & 28 & 42 & \\
\hline No & 73 & 35 & 38 & \\
\hline
\end{tabular}

criteria of World Health Organization and the American Joint Committee on Cancer (AJCC) $(13,14)$. Patients who underwent preoperative chemoradiation were excluded since it affects the ratio of fibrosis to cancer cells (15).

The study was approved by the Ethics Committee of The First Affiliated Hospital of Wannan Medical College (Wuhu, China). Patients who participated in this research had complete clinical data. Signed informed consents were obtained from the patients and/or the guardians.

Formalin-fixed and paraffin-embedded (FFPE) tumor tissue blocks were retrieved from the database of the Department of Pathology, Yijishan Hospital of Wannan
Medical College, sectioned, and stained with hematoxylin and eosin (H\&E) for histological analysis of the primary tumor stage and nodal status. The clinicopathological characteristics of the patients with pancreatic head cancer are summarized in Table I. The patients were followed up after the operation by telephone conversation and/or out-patient clinic interviews.

Classification of $P F$. The tumor specimens were classified into 3 categories according to the degree of PF: negative $(<10 \%$ fibrotic change), moderate (11-30\%) and severe (>30\%). 
Table II. Univariate survival analysis after resection of pancreatic head cancer.

\begin{tabular}{|c|c|c|c|c|}
\hline Characteristics & No. of patients & HR & $95 \% \mathrm{CI}$ & P-value \\
\hline \multicolumn{5}{|l|}{ Age (years) } \\
\hline$<70$ & 104 & 0.923 & $0.611-1.394$ & 0.704 \\
\hline$\geq 70$ & 39 & 1 & & \\
\hline \multicolumn{5}{|l|}{ Sex } \\
\hline Female & 61 & 1.051 & $0.746-1.480$ & 0.777 \\
\hline Male & 82 & 1 & & \\
\hline \multicolumn{5}{|c|}{ Intraoperative blood transfusion } \\
\hline Yes & 42 & 1.182 & $0.790-1.767$ & 0.790 \\
\hline No & 101 & 1 & & \\
\hline \multicolumn{5}{|l|}{ Vein resection } \\
\hline Yes & 25 & 1.646 & $1.048-2.588$ & 0.031 \\
\hline No & 118 & 1 & & \\
\hline \multicolumn{5}{|l|}{ Grading } \\
\hline G1/2 & 114 & 1 & & \\
\hline $\mathrm{G} 3 / 4$ & 29 & 1.843 & $1.135-2.993$ & 0.013 \\
\hline \multicolumn{5}{|l|}{ T stage } \\
\hline $\mathrm{T} 1 / 2$ & 21 & 0.683 & $0.414-1.128$ & 0.136 \\
\hline $\mathrm{T} 3 / 4$ & 122 & 1 & & \\
\hline \multicolumn{5}{|c|}{ Resection margin } \\
\hline Negative & 105 & 1 & & \\
\hline Positive & 38 & 1.542 & $1.022-2.324$ & 0.039 \\
\hline \multicolumn{5}{|l|}{ Nodal status } \\
\hline Negative & 82 & 1 & & \\
\hline Positive & 61 & 1.790 & $1.257-2.556$ & 0.001 \\
\hline \multicolumn{5}{|c|}{ Preoperative CA19-9 (U/ml) } \\
\hline$<37$ & 21 & 1.783 & $1.070-2.972$ & 0.026 \\
\hline$\geq 37$ & 122 & 1 & & \\
\hline \multicolumn{5}{|c|}{ No. of examined nodes } \\
\hline$<12$ & 52 & 0.883 & $0.575-1.178$ & 0.288 \\
\hline$\geq 12$ & 91 & 1 & & \\
\hline \multicolumn{5}{|c|}{ Peritumoral fibrosis } \\
\hline Presence & 85 & 3.079 & $1.975-4.844$ & $<0.001$ \\
\hline Absence & 58 & 1 & & \\
\hline \multicolumn{5}{|l|}{ Complications } \\
\hline Yes & 70 & 0.885 & $0.624-1.255$ & 0.493 \\
\hline No & 73 & 1 & & \\
\hline
\end{tabular}

P-value in bold print indicates statistical significance.

Statistical analysis. All statistical analyses were performed using the R3.1.3 program (http://www.R-project.org). Pearson's Chi-square test and Fisher exact probability test were performed to analyze the correlation between different parameters. Univariate Kaplan-Meier analysis was performed to assess the prognostic factors for survival, as well as compared using the two-sided log-rank test. The Cox proportional hazard model (forward selection strategy using a likelihood ratio statistic; inclusion $\mathrm{P}=0.05$ ) was performed by multivariate survival analysis, including hazard ratios and their $95 \%$ confidence interval. P-values $<0.05$ were considered statistically significant.

\section{Results}

Clinicopathological characteristics of the patients. The clinicopathological features of patients with PHC who underwent 
Table III. Multivariate survival analysis after resection of pancreatic head cancer.

\begin{tabular}{|c|c|c|c|c|}
\hline Characteristics & No. of patients & HR & $95 \% \mathrm{CI}$ & P-value \\
\hline \multicolumn{5}{|l|}{ Vein resection } \\
\hline Yes & 25 & 2.251 & $1.348-3.758$ & 0.002 \\
\hline No & 118 & 1 & & \\
\hline \multicolumn{5}{|l|}{ Grading } \\
\hline $\mathrm{G} 1 / 2$ & 114 & 1 & & \\
\hline $\mathrm{G} 3 / 4$ & 29 & 1.856 & $1.145-3.009$ & 0.012 \\
\hline \multicolumn{5}{|c|}{ Resection margin } \\
\hline Negative & 105 & 1 & & \\
\hline Positive & 38 & 1.977 & $1.212-3.225$ & 0.006 \\
\hline \multicolumn{5}{|l|}{ Nodal status } \\
\hline Negative & 82 & 1 & & \\
\hline Positive & 61 & 2.973 & $1.947-4.540$ & $<0.001$ \\
\hline \multicolumn{5}{|c|}{ Preoperative CA19-9 (U/ml) } \\
\hline$<37$ & 21 & 2.398 & $1.166-4.926$ & 0.017 \\
\hline$\geq 37$ & 122 & 1 & & \\
\hline \multicolumn{5}{|c|}{ Peritumoral fibrosis } \\
\hline Presence & 85 & 1.392 & $1.038-1.869$ & 0.027 \\
\hline Absence & 58 & 1 & & \\
\hline
\end{tabular}

P-value in bold print indicates statistical significance.

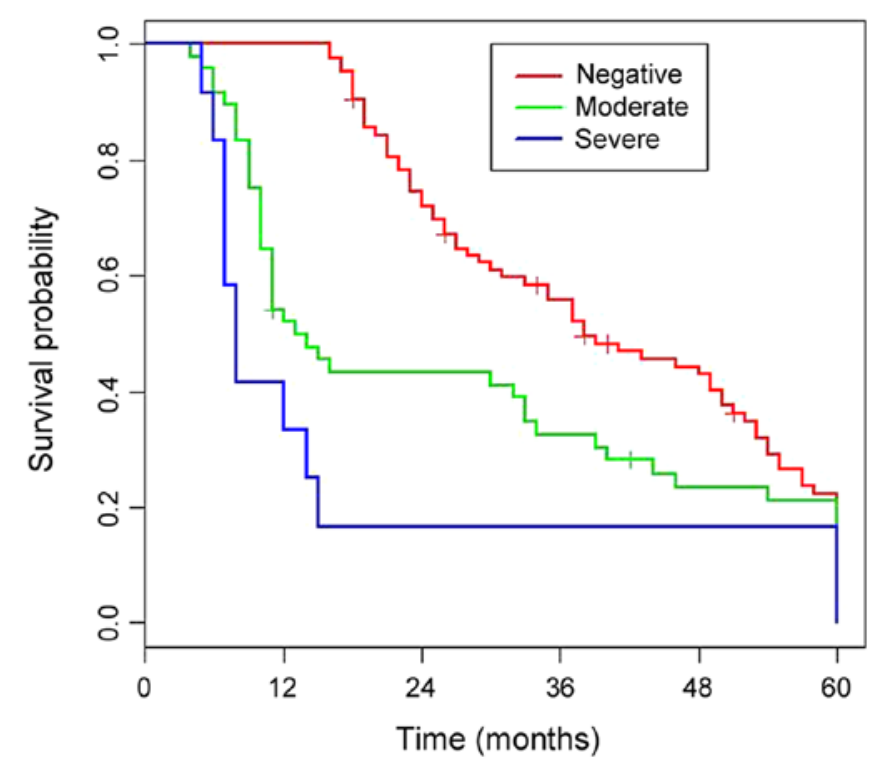

Figure 1. Correlation between post resection overall survival and the absence/presence of peritumoral fibrosis.

pancreatic tumor resection are summarized in Table I. The median age of patients was 64 years (range $32-85$ years). PF was not significantly correlated with any of the clinicopathological factors.

Univariate survival analysis. No patient died during the postoperative course. The median follow-up duration of the

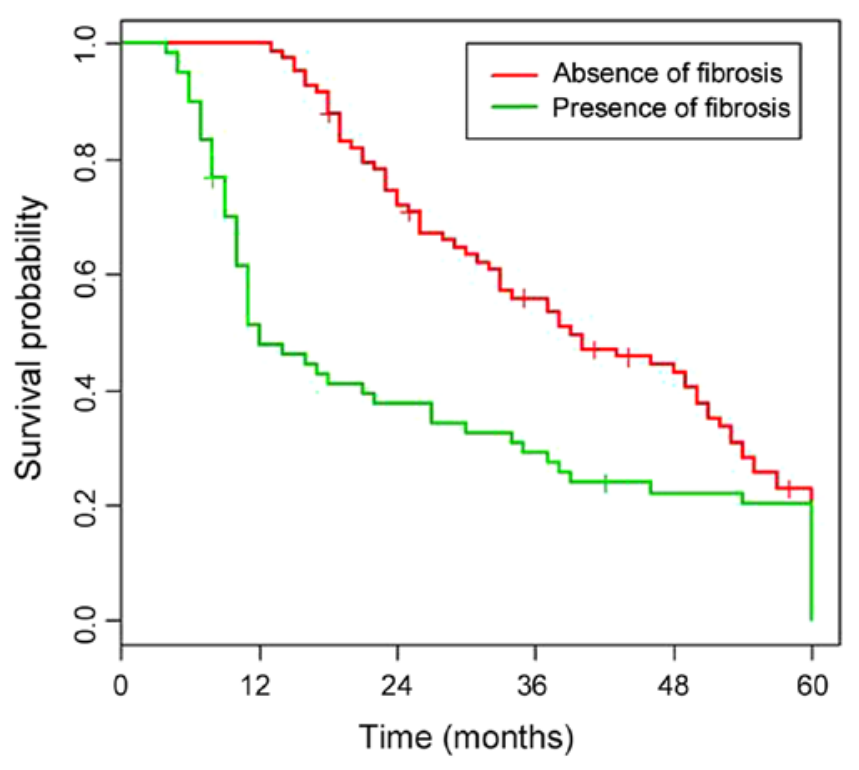

Figure 2. Correlation between post resection overall survival and the degree of peritumoral fibrosis.

entire cohort was 28.7 months (range 5.3-60 months), and the median survival was 1.95 years. The cumulative 3 - and 5-year survival rates were 31 and $19 \%$, respectively. Univariate analysis (Table II) showed that vein resection, resection margin, grading, nodal status, preoperative values of CA19-9 and PF were significantly associated with survival. Patients with PF had significantly worse survival compared to those without 
Normal

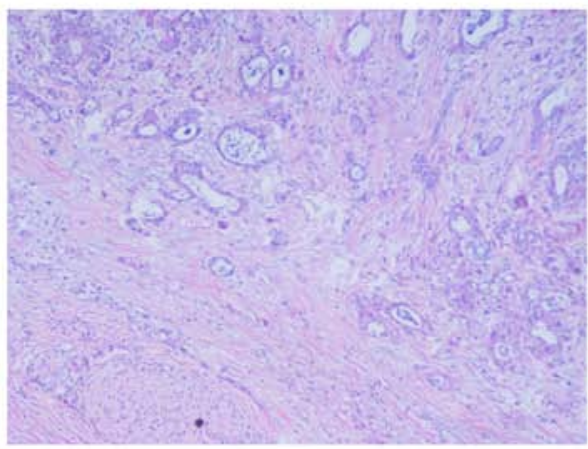

Moderate

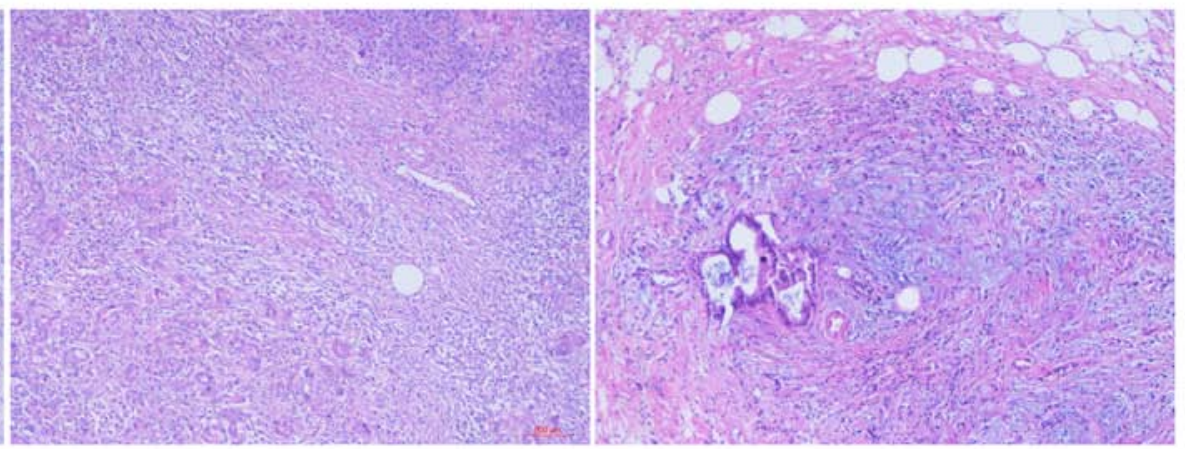

Figure 3. Histological analysis of a tumor specimen with peritumoral fibrosis (asterisk) (hematoxylin and eosin, $\mathrm{x} 100$ ).

(HR 3.079; $\mathrm{P}<0.001$ ) (Fig. 1). The overall survival (OS) of patients with mild and severe $\mathrm{PF}$ is shown in Fig. $2(\mathrm{P}=0.02)$.

Multivariate survival analysis. Multivariate analysis (Table III) indicated that resection margin, vein resection, grading, preoperative values of CA19-9, nodal status and PF were all independent predictive factors of survival. The survival of patients with PF was significantly worse than those without (HR 1.392; $\mathrm{P}=0.027$ ).

\section{Discussion}

Correlation between the presence of PF and various clinicopathological parameters were evaluated in 143 pancreatic head cancer patients who underwent tumor resection. This is the first study to show the association between PF and poor post-resection overall survival in pancreatic cancer patients, and identify it as an independent negative prognostic factor (Fig. 3).

Scarce data is available on the association between PF and the clinico-pathological characteristics of pancreatic cancers. A recent study indicated the diagnostic importance of histological PF in PHCs (16). Consistent with this, we found that the presence of PF, as well as the severity of necrosis, was associated with significantly decreased OS. In addition, PF was also identified as independent prognostic factor of post-resection outcome. Based on our results, we hypothesize a diagnostic value of PF in evaluating the post-resection outcome in PHC patients. A rational clinical translation of these results suggests standardized utilization of PF as a prognostic tool in the scope of pathological evaluation of resected specimens from patients suffering from pancreatic head cancer.

The cause of fibrosis in PHC and the mechanisms underlying the poor clinical outcome in patients with PF remain largely unknown. One hypothesis is that inflammation, which has been recently described as the seventh hallmark of cancer $(17,18)$, likely plays a role in the formation of fibrotic masses as well. Furthermore, there is evidence indicating that pancreatic stellate cells trigger fibrosis through various stromal interactions and allow wound healing, thereby promoting cancer cell invasion and dissemination (19-21). Despite recent advances in our understanding of the genetic and cellular basis of pancreatic head cancer progression, its diagnostic and prognostic evaluation is still mostly dependent on histopathological assessment. The histopathological parameters such as tumor grading and
$\mathrm{PF}$ are easy to evaluate, and can allow individualized risk assessment and identify patients at high risk of poor outcome.

There are several limitations to our study, including those inherent to retrospective analyses. In addition, the surgical resection was performed by multiple surgeons, and reliable histological evaluation was only possible with the resected tumor specimens. This can be circumvented in future with high-resolution magnetic resonance imaging (MRI), which can allow non-invasive in vivo visualization at a 3D spatial resolution of up to $50 \mu \mathrm{m}$ (22-24). Despite these limitations, our data suggest that PF is a simple diagnostic tool that can evaluate patients' outcome after resection of PHC.

In conclusion, $\mathrm{PF}$ is an independent prognostic factor of PHC and predictive of poor survival after resection. This indicates its potential role in pancreatic cancer progression as well as its diagnostic utility. Future prospective trials are needed to assess the value of PF as a criterion for adjuvant treatment.

\section{Acknowledgements}

We are grateful to Professor Entao Sun from the Institute of Testing, Wannan Medical College for helping with our research.

\section{Funding}

This study was supported by Anhui Provincial Centralized Local Science and Technology Development Special Project (YDZX20183400004899); Anhui Science and Technology Research Fund Project (1501041156).

\section{Availability of data and materials}

The datasets used and/or analyzed during the present study are available from the corresponding author on reasonable request.

\section{Authors' contributions}

$\mathrm{PC}$ wrote the manuscript and was responsible for the collection and classification of tumor samples. YW and XF interpreted and analyzed the data. XW designed the study and performed the experiments. GW was responsible for the analysis and discussion of the data. All authors read and approved the final manuscript. 


\section{Ethics approval and consent to participate}

The study was approved by the Ethics Committee of The First Affiliated Hospital of Wannan Medical College (Wuhu, China). Patients who participated in this research had complete clinical data. Signed informed consents were obtained from the patients and/or the guardians.

\section{Patient consent for publication}

Not applicable.

\section{Competing interests}

The authors declare that they have no competing interests.

\section{References}

1. Liu Z, Luo G, Guo M, Jin K, Xiao Z, Liu L, Liu C, Xu J, Ni Q, Long J, et al: Lymph node status predicts the benefit of adjuvant chemoradiotherapy for patients with resected pancreatic cancer. Pancreatology 15: 253-258, 2015.

2. Lim JE, Chien MW and Earle CC: Prognostic factors following curative resection for pancreatic adenocarcinoma: A population-based, linked database analysis of 396 patients. Ann Surg 237: 74-85, 2003.

3. Siegel RL, Miller KD and Jemal A: Cancer statistics, 2019. CA Cancer J Clin 69: 7-34, 2019.

4. Harris AL: Hypoxia - a key regulatory factor in tumour growth. Nat Rev Cancer 2: 38-47, 2002.

5. Vaupel P and Mayer A: Hypoxia in cancer: Significance and impact on clinical outcome. Cancer Metastasis Rev 26: 225-239, 2007.

6. Bristow RG and Hill RP: Hypoxia and metabolism. Hypoxia, DNA repair and genetic instability. Nat Rev Cancer 8: 180-192, 2008.

7. Frank I, Blute ML, Cheville JC, Lohse CM, Weaver AL and Zincke H: An outcome prediction model for patients with clear cell renal cell carcinoma treated with radical nephrectomy based on tumor stage, size, grade and necrosis: The SSIGN score. J Urol 168: 2395-2400, 2002.

8. Fisher ER, Palekar AS, Gregorio RM, Redmond C and Fisher B: Pathological findings from the national surgical adjuvant breast project (Protocol No. 4). IV. Significance of tumor necrosis. Hum Pathol 9: 523-530, 1978.

9. Swinson DE, Jones JL, Richardson D, Cox G, Edwards JG and O'Byrne KJ: Tumour necrosis is an independent prognostic marker in non-small cell lung cancer: Correlation with biological variables. Lung Cancer 37: 235-240, 2002.

10. Hiraoka N, Ino Y, Sekine S, Tsuda H, Shimada K, Kosuge T, Zavada J, Yoshida M, Yamada K, Koyama T, et al: Tumour necrosis is a postoperative prognostic marker for pancreatic cancer patients with a high interobserver reproducibility in histological evaluation. Br J Cancer 103: 1057-1065, 2010.
11. Pearlman BL and Traub N: Sustained virologic response to antiviral therapy for chronic hepatitis $\mathrm{C}$ virus infection: A cure and so much more. Clin Infect Dis 52: 889-900, 2011.

12. Valent P, Orazi A, Büsche G, Schmitt-Gräff A, George TI, Sotlar K, Streubel B, Beham-Schmid C, Cerny-Reiterer S, Krieger O, et al: Standards and impact of hematopathology in myelodysplastic syndromes (MDS). Oncotarget 1: 483-496, 2010.

13. Kwon W, He J, Higuchi R, Son D, Lee SY, Kim J, Kim H Kim SW, Wolfgang CL, Cameron JL, et al: Multinational validation of the American Joint Committee on Cancer 8th edition pancreatic cancer staging system in a pancreas head cancer cohort. J Hepatobiliary Pancreat Sci 25: 418-427, 2018.

14. Liu R, Wakabayashi G, Kim HJ, Choi GH, Yiengpruksawan A, Fong Y, He J, Boggi U, Troisi RI, Efanov M, et al: International consensus statement on robotic hepatectomy surgery in 2018. World J Gastroenterol 25: 1432-1444, 2019.

15. Chun YS, Cooper HS, Cohen SJ, Konski A, Burtness B, Denlinger CS, Astsaturov I, Hall MJ and Hoffman JP: Significance of pathologic response to preoperative therapy in pancreatic cancer. Ann Surg Oncol 18: 3601-3607, 2011.

16. Tomita Y, Azuma K, Nonaka Y, Kamada Y, Tomoeda M, Kishida M, Tanemura M and Miyoshi E: Pancreatic fatty degeneration and fibrosis as predisposing factors for the development of pancreatic ductal adenocarcinoma. Pancreas 43: 1032-1041, 2014.

17. Vakkila $J$ and Lotze MT: Inflammation and necrosis promote tumour growth. Nat Rev Immunol 4: 641-648, 2004.

18. Hanahan D and Weinberg RA: Hallmarks of cancer: The next generation. Cell 144: 646-674, 2011.

19. Bachem MG, Schünemann M, Ramadani M, Siech M, Beger H, Buck A, Zhou S, Schmid-Kotsas A and Adler G: Pancreatic carcinoma cells induce fibrosis by stimulating proliferation and matrix synthesis of stellate cells. Gastroenterology 128: 907-921, 2005.

20. Lee JM, Dedhar S, Kalluri R and Thompson EW: The epithelialmesenchymal transition: New insights in signaling, development, and disease. J Cell Biol 172: 973-981, 2006.

21. Vonlaufen A, Joshi S, Qu C, Phillips PA, Xu Z, Parker NR, Toi CS, Pirola RC, Wilson JS, Goldstein D, et al: Pancreatic stellate cells: Partners in crime with pancreatic cancer cells. Cancer Res 68: 2085-2093, 2008.

22. Jacoby C, Borg N, Heusch P, Sauter M, Bönner F, Kandolf R, Klingel K, Schrader J and Flögel U: Visualization of immune cell infiltration in experimental viral myocarditis by (19)F MRI in vivo. MAGMA 27: 101-106, 2014

23. van Heeswijk RB, De Blois J, Kania G, Gonzales C, Blyszczuk P, Stuber M, Eriksson U and Schwitter J: Selective in vivo visualization of immune-cell infiltration in a mouse model of autoimmune myocarditis by fluorine-19 cardiac magnetic resonance. Circ Cardiovasc Imaging 6: 277-284, 2013.

24. Figueiredo S, Cutrin JC, Rizzitelli S, De Luca E, Moreira JN, Geraldes CF, Aime S and Terreno E: MRI tracking of macrophages labeled with glucan particles entrapping a water insoluble paramagnetic Gd-based agent. Mol Imaging Biol 15: 307-315, 2013.

This work is licensed under a Creative Commons Attribution-NonCommercial-NoDerivatives 4.0 International (CC BY-NC-ND 4.0) License. 